\title{
Correction to: How sensitive are adults to the role of morphology in spelling?
}

\author{
Rebecca Treiman $^{1}$ - Sloane Wolter ${ }^{1}$ - Brett Kessler ${ }^{1}$
}

Accepted: 26 January 2021 / Published online: 2 February 2021

(C) Springer Nature B.V. 2021

The original online version of this article was revised: Reference V. Heyer has been updated.

Publisher's Note Springer Nature remains neutral with regard to jurisdictional claims in published maps and institutional affiliations.

The original article can be found online at https://doi.org/10.1007/s11525-020-09356-4

$\otimes$ R. Treiman rtreiman@wustl.edu

1 Department of Psychological and Brain Sciences, Washington University in St. Louis, St. Louis, USA 